\title{
Quantitative Studies of Co(II)-Thymoquinone Complex using Cyclic Voltammetry
}

\author{
Farah Kishwar* \\ Department of Chemistry, Federal Urdu University of Arts, Science and Technology, Gulshan-e-Iqbal Campus, 75300, Karachi, Pakistan.
}

Received 16 May 2016, revised 26 July 2016, accepted 17 August 2016.

\begin{abstract}
In this research quantitative studies of Co(II)-thymoquinone complex was performed using cyclic voltammetry. The electrodes used were glassy carbon as working, saturated calomel as reference and platinum as auxiliary electrode. All the work was done at standard temperature $\left(25 \pm 1^{\circ} \mathrm{C}\right)$ in aqueous medium using $\mathrm{NaCl}$ as supporting electrolyte. Effects of different parameters, i.e. concentration and metal-ligand ratios on complex formation were investigated. Observations obtained by varying the metal-ligand ratio suggested a quasi-reversible electron transfer process in the complex. The effect of concentration followed the Randles-Sevcik equation. Values of the standard electrode potential $\left(E^{\circ}\right)$, diffusion coefficient (D), transfer coefficients $(\alpha$ and $\beta$ ) and different electrochemical parameters were also calculated. The $\mathrm{E}^{\circ}$ for the complex was found to be $0.288 \pm 0.01 \mathrm{~V}$. The $\alpha$ values ranged between $0.676 \pm 0.02-1.00 \pm 0.02$ whereas the values of $\beta$ were found to be $0.758 \pm 0.01-1.20 \pm 0.01$ respectively. Linear regression showed that cyclic voltammetry could be useful for the quantification of Co(II)-thymoquinone complex in pharmaceutical analysis.
\end{abstract}

\section{KEYWORDS}

Co(II)-thymoquinone complex, cyclic voltammetry, effect of concentration and metal-ligand ratio, Randles-Sevcik equation, quasi-reversible behaviour.

\section{Introduction}

Cobalt is one of the trace elements which are essential for human health and is found as the key mineral of vitamin $B_{12}{ }^{1,2}$ It is necessary for the formation of erythrocytes, synthesis of DNA, RNA and myelin, red blood cells formation and in repairing nerve tissues. In addition iron, calcium and vitamin $\mathrm{B}_{6}$ also require it to perform their roles. Metabolism of some important nutrients such as carbohydrates and proteins takes place in the presence of vitamin $\mathrm{B}_{12}{ }^{1}$ Hence deficiency as well as toxicity of cobalt can cause several severe complications. Some of them are pernicious anaemia, nervous disorders, paralysis ${ }^{3-6}$, thyroid stimulation and polycythemia. ${ }^{7} \mathrm{Co}(\mathrm{II})$ forms numerous complexes, out of which its octahedral and tetrahedral complexes are most common but it forms five-coordinate and square planer complexes also. ${ }^{8,9}$

Thymoquinone, shown in Fig. 1, is a bio-active component of volatile oil of Nigella sativa ${ }^{10,11}$ which has been found to possess hundreds of biological activities. ${ }^{12-17}$ It is a strong antioxidant $t^{17,18}$ and can form complexes with several metals. ${ }^{19,20}$ These properties may play very important role in its pharmacological action.

Cyclic voltammetry is an extensively used electro-chemical technique and is equally beneficial for qualitative as well as quantitative approach. On the one hand it helps to determine kinetics of electron transfer and different parameters like peak potentials, peak currents, etc., whereas, on the other hand, it gives information about coupled electrochemical reaction and interfacial adsorption-desorption behaviour of electro-active species. $^{21,22}$ Furthermore, it is also used to acquire knowledge about the formation of any possible intermediates during different redox reactions. ${ }^{23,24}$ Hence it is a very popular and reliable electrochemical technique and is widely applied nowadays. ${ }^{25-29}$

The aim of this study was to carry out a quantitative study of * To whom correspondence should be addressed. E-mail: farahkishwar@yahoo.com
Co(II) thymoquinone complex in order to examine its behaviour. For this purpose effects of variation of some parameters, such as metal-ligand ratio and concentration on complexation of $\mathrm{Co}(\mathrm{II})$ and thymoquinone were studied.

\section{Experimental}

\subsection{Chemicals}

Analytical grade reagents were used without further purification. Thymoquinone (99\%) was purchased from MP Biomedicals, LLC, Santa Ana, CA, United States and sodium chloride $(\geq 99.5 \%)$, cobalt acetate tetra hydrate (99.0-101.0 \%) and methanol (99.5\%) from Merck KGaA Darmstadt, Germany.

\subsection{Instrumentation}

CHI-760 D Electrochemical work station (CH Instruments, Inc., Austin, USA) was used for cyclic voltammetric study. Three electrodes, a glassy carbon (Model CHI 104, CH Instruments, Inc., Austin, USA; area of the electrode $=0.07065 \mathrm{~cm}^{2}$ ), a saturated calomel and a platinum wire electrode, were used as working, reference and auxiliary electrodes respectively. Re-polishing of glassy carbon electrode was done by alumina (the particle size of which was 0.3 micron).<smiles>CC1=CC(=O)C(C(C)C)=CC1=O</smiles>

Figure 1 Thymoquinone. 


\subsection{Sample Preparation}

Supporting electrolyte was $\mathrm{NaCl}(0.1 \mathrm{M})$ whereas $5 \times 10^{-3} \mathrm{M}$ solution of thymoquinone and $\mathrm{Co}\left(\mathrm{CH}_{3} \mathrm{COO}\right)_{2} \cdot 4 \mathrm{H}_{2} \mathrm{O}$ were used as analyte solutions. $10 \%$ methanol was also used in their preparation in addition to $0.1 \mathrm{M} \mathrm{NaCl}$.

\subsection{Cyclic Voltammetric Studies}

All the work was performed at $0.1 \mathrm{~V} / \mathrm{s}$ whereas current sensitivity was $1 \times 10^{-4} \mathrm{~A} / \mathrm{V}$. The applied potential range was set from $-0.40 \mathrm{~V}$ to $+1.00 \mathrm{~V}$ and then reversed back to the initial potential value. In order to observe the effect of concentration, solutions having a concentration range of $0.02 \times 10^{-3} \mathrm{M}$ to $1.2 \times 10^{-3} \mathrm{M}$ were used while in order to examine the effect of metal-ligand ratio, complex solutions with metal-ligand ratios of 1:1-1:5 were used. Triplicate analysis was carried out in both the cases. At first the baseline was recorded and after that cyclic voltammograms of complex solutions were run. In each case the volume of the solution was $15 \mathrm{~mL}$.

\section{Results and Discussion}

\subsection{Effect of Complex Concentration}

For this purpose a calibration curve was constructed using the Randles-Sevcik equation. ${ }^{30}$ The cyclic voltammograms clearly revealed dependence of peak current on concentration as revealed by Fig. 2 . In case of a solution having concentration $0.02 \times 10^{-3} \mathrm{M}$ only the oxidative wave was observed and no reductive peak was seen whereas in other cases both peaks (1 and 2) were significant. At relatively high concentrations, i.e. from $0.4 \times 10^{-3} \mathrm{M}$ to $1.2 \times 10^{-3} \mathrm{M}$, a smaller peak (3) also appeared in the oxidative scan only but here a positive shift of the peak was also noted. As for the solution with a complex concentration of
$0.4 \times 10^{-3} \mathrm{M}$, the peak was observed to have an oxidative potential at $0.097 \mathrm{~V}$ but when the concentration was increased to $1.2 \times 10^{-3} \mathrm{M}$ it shifted to $0.138 \mathrm{~V}$. This additional peak might be due to formation of another complex as a result of a probable reaction between oxidized species and the solvent but absence of a reverse peak suggests that this could be linked to the complex's instability.

Linear regression revealed a direct relationship between current and concentration within the range $0.02 \times 10^{-3} \mathrm{M}$ to $1.2 \times 10^{-3} \mathrm{M}$ as seen in Fig. 3 .

This is testimony that the concentration of the complex follows the Randles-Sevick equation as shown in Table 1 and no adsorption of complex at the electrode surface occurred.

As seen in Fig. 4, the plot of peak potential against log of concentration showed straight lines indicating no reasonable change in the peak potential with the change of concentration.

\subsection{Effect of Metal-Ligand Ratio}

All complex solutions showed clear anodic and cathodic peaks (1 and 2) except the solution having metal-ligand ratio 1:1, which gave a cathodic peak only at $-0.302 \mathrm{~V}$ as seen in Fig. 5. Another small oxidative peak (3) was noted at $0.037 \mathrm{~V}$ in case of complex solution with 1:2 metal-ligand ratio which shifted positively with the increase in metal-ligand ratio. This resulting oxidation potential may be due to formation of any extra complex species as a result of an increase in the concentration of the ligand but the absence of reverse peak again shows that it was due to instability of the complex.

All observations in this experiment suggested that the complex follows quasi-reversible behaviour. ${ }^{22}$ For instance, $\mathrm{I}_{\mathrm{pa}} / \mathrm{I}_{\mathrm{pc}}$ was found to be less than one whereas the difference between anodic and cathodic potentials was found more than $59 / \mathrm{n} \mathrm{mV}$. In each

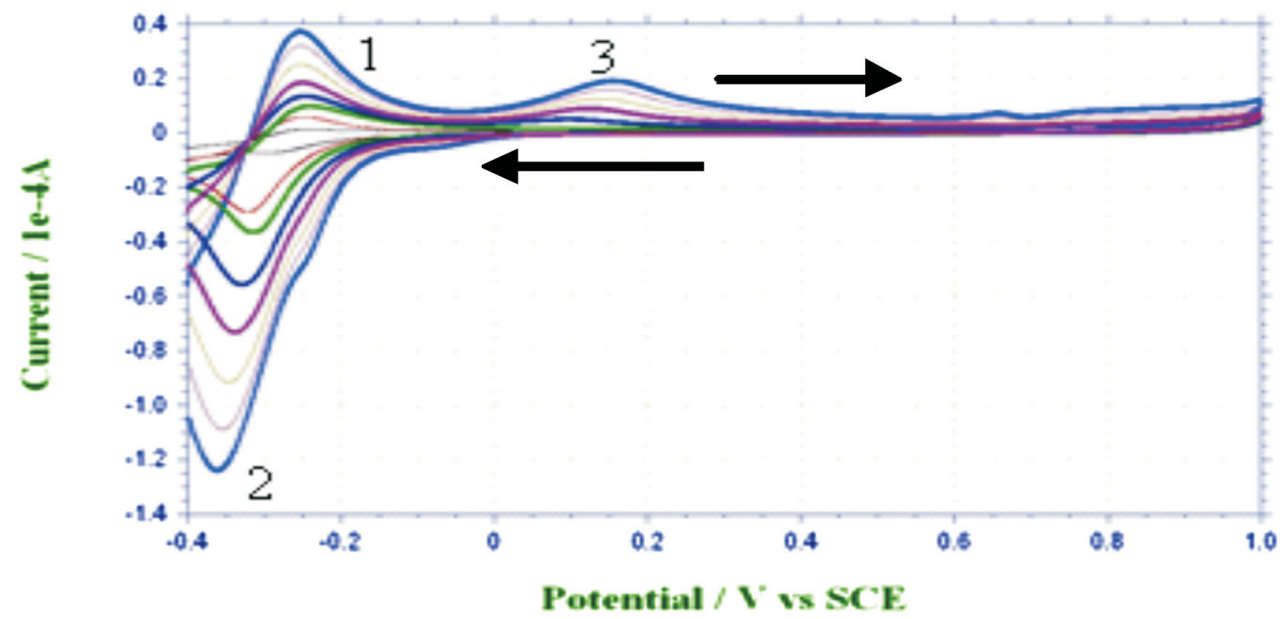

Figure 2 Cyclic voltammograms of Co(II)thymoquinone complex solutions showing effect of concentration (concentrations $=0.02 \times 10^{-3}, 0.1 \times 10^{-3}$, $\left.0.2 \times 10^{-3}, 0.4 \times 10^{-3}, 0.6 \times 10^{-3}, 0.8 \times 10^{-3}, 1.0 \times 10^{-3}, 1.2 \times 10^{-3} \mathrm{M}\right)$.

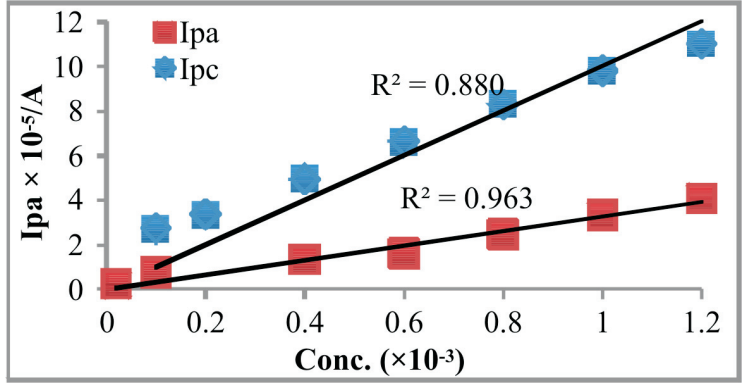

Figure 3 Plot of anodic and cathodic peak current against concentration of $\mathrm{Co}(\mathrm{II})$-thymoquinone complex.

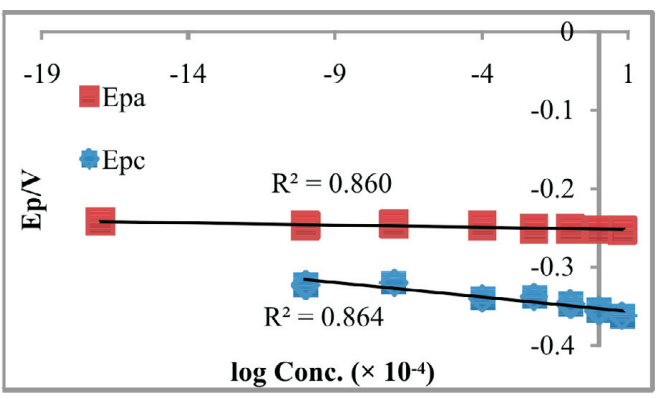

Figure 4 Variation of anodic and cathodic peak potential with log of concentration on cyclic voltammogram of $\mathrm{Co}(\mathrm{II})$-thymoquinone complex. 
Table 1 Electrochemical parameters obtained from cyclic voltammograms of Co(II)-thymoquinone complex solutions with different concentrations $(\mathrm{n}=3)$.

\begin{tabular}{|c|c|c|c|c|}
\hline Conc. $\left(\times 10^{-3} \mathrm{M}\right)$ & $\begin{array}{c}\mathrm{E}_{\mathrm{pa}}( \pm \mathrm{SD})^{*} \\
/ \mathrm{V}\end{array}$ & $\mathrm{I}_{\mathrm{pa}}( \pm \mathrm{SD}) \times 10^{-5}$ & $\mathrm{I}_{\mathrm{pa}} / \mathrm{I}_{\mathrm{pc}}$ & $\begin{array}{c}\beta \mathrm{n}_{\mathrm{b}}= \\
0.048 / \mathrm{E}_{\mathrm{pa}}-\mathrm{E}_{\mathrm{p} / 2}( \pm \mathrm{SD})\end{array}$ \\
\hline 0.02 & $-0.242 \pm 0.01$ & $0.252 \pm 0.01$ & - & $1.20 \pm 0.01$ \\
\hline 0.1 & $-0.247 \pm 0.01$ & $0.785 \pm 0.01$ & 0.287 & $1.20 \pm 0.01$ \\
\hline 0.2 & $-0.245 \pm 0.01$ & $1.490 \pm 0.01$ & 0.443 & $1.10 \pm 0.01$ \\
\hline 0.4 & $-0.247 \pm 0.01$ & $1.341 \pm 0.01$ & 0.270 & $1.10 \pm 0.01$ \\
\hline 0.6 & $-0.251 \pm 0.01$ & $1.618 \pm 0.01$ & 0.244 & $1.20 \pm 0.02$ \\
\hline 0.8 & $-0.251 \pm 0.02$ & $2.460 \pm 0.02$ & 0.296 & $1.20 \pm 0.02$ \\
\hline 1.0 & $-0.252 \pm 0.01$ & $3.330 \pm 0.01$ & 0.339 & $1.00 \pm 0.01$ \\
\hline 1.2 & $-0.253 \pm 0.02$ & $4.094 \pm 0.02$ & 0.371 & $1.00 \pm 0.02$ \\
\hline Conc. $\left(\times 10^{-3} \mathrm{M}\right)$ & $\frac{\mathrm{E}_{\mathrm{pc}}( \pm \mathrm{SD})}{/ \mathrm{V}}$ & $\underset{\mathrm{pc}}{\mathrm{I}_{\mathrm{c}}( \pm \mathrm{SD}) \times 10^{-5}}$ & $\underset{\mathrm{pE}=\mathrm{E}_{\mathrm{pa}}-\mathrm{E}_{\mathrm{pc}}( \pm \mathrm{SD})}{/ \mathrm{N}}$ & $\begin{array}{c}\alpha \mathrm{n}_{\mathrm{a}}= \\
0.048 / \mathrm{E}_{\mathrm{pc}}-\mathrm{E}_{\mathrm{pc} / 2}( \pm \mathrm{SD})\end{array}$ \\
\hline 0.02 & - & - & - & - \\
\hline 0.1 & $-0.323 \pm 0.02$ & $2.733 \pm 0.01$ & $0.076 \pm 0.01$ & $0.923 \pm 0.01$ \\
\hline 0.2 & $-0.316 \pm 0.01$ & $3.365 \pm 0.02$ & $0.071 \pm 0.01$ & $1.00 \pm 0.02$ \\
\hline 0.4 & $-0.330 \pm 0.01$ & $4.967 \pm 0.01$ & $0.083 \pm 0.01$ & $0.842 \pm 0.01$ \\
\hline 0.6 & $-0.337 \pm 0.01$ & $6.637 \pm 0.01$ & $0.086 \pm 0.01$ & $0.814 \pm 0.01$ \\
\hline 0.8 & $-0.347 \pm 0.01$ & $8.302 \pm 0.01$ & $0.096 \pm 0.01$ & $0.787 \pm 0.01$ \\
\hline 1.0 & $-0.355 \pm 0.02$ & $9.817 \pm 0.02$ & $0.103 \pm 0.02$ & $0.696 \pm 0.02$ \\
\hline 1.2 & $-0.362 \pm 0.01$ & $11.03 \pm 0.01$ & $0.109 \pm 0.02$ & $0.676 \pm 0.02$ \\
\hline
\end{tabular}

${ }^{*} \mathrm{SD}=$ standard deviation.

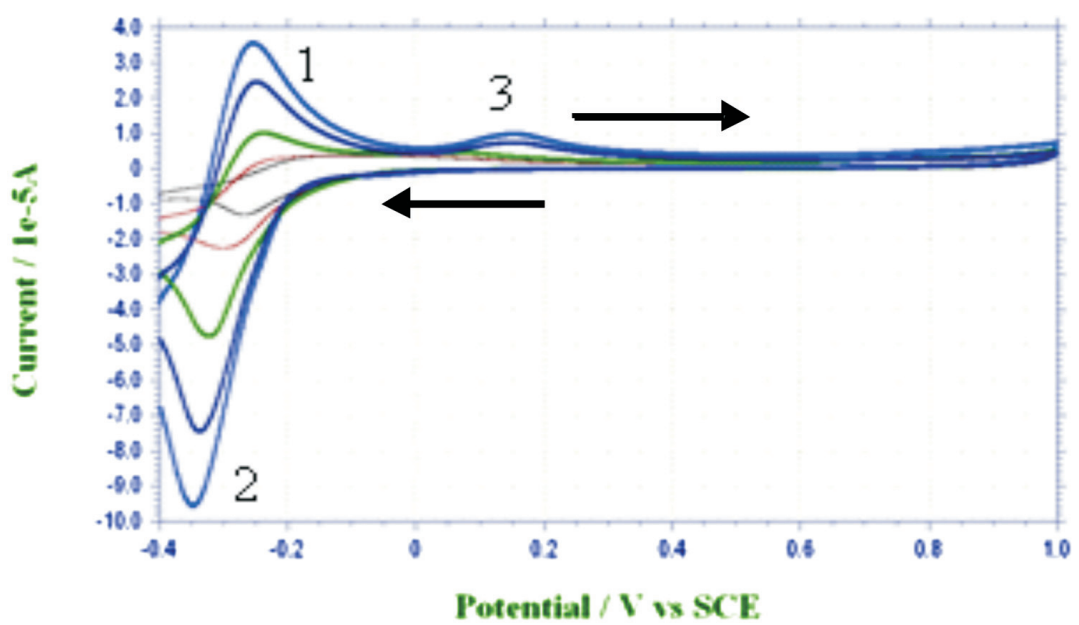

Figure 5 Cyclic voltammogram of $\mathrm{Co}(\mathrm{II})$-thymoquinone complex showing effect of metal-ligand ratio (metal-ligand ratio = 1:1, 1:2, 1:3, 1:4, 1:5).

case the values of $\alpha$ and $\beta$ were also calculated as illustrated in Table 2. Fig. 6 shows that the plot of peak potentials versus metal-ligand ratio gave straight lines with good $R^{2}$ value.

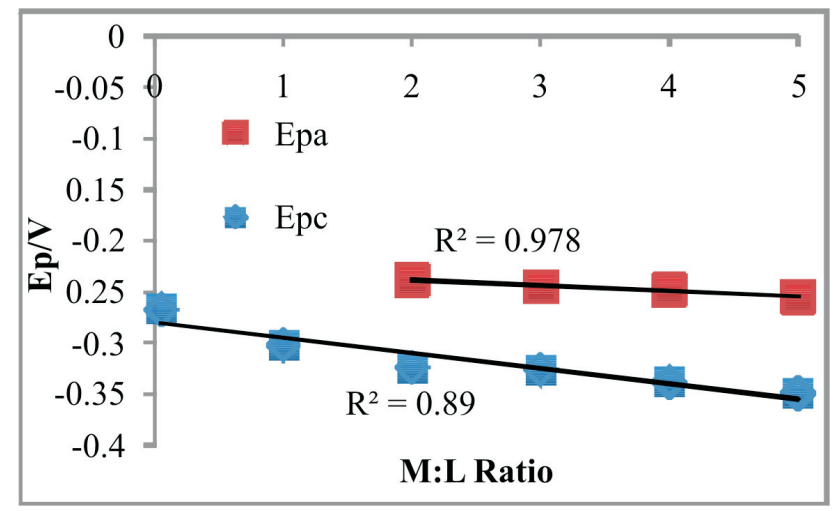

Figure 6 Variation of anodic and cathodic peak potentials with change of metal-ligand ratio in cyclic voltammograms of $\mathrm{Co}(\mathrm{II})$-thymoquinone complex.

\subsection{Diffusion Coefficient Analysis}

It is an important constant for different complexes and could be easily and accurately obtained using cyclic voltammetry. ${ }^{31}$ For the studied complex, it was calculated by Randles-Sevcik equation. ${ }^{30}$ The area of electrode (A) and number of electron transferred (n) were $0.0706 \mathrm{~cm}^{2}$ and 1 respectively. Its value was found to be more or less unaffected by varying concentrations in case of forward scan as seen in Table 3; however, for the reverse scan diffusion coefficient was obtained in the range of $10^{-4}$ in each case. As far as effect of metal-ligand ratios is concerned, values of diffusion coefficient varied by changing the ratio, which shows some complications or the impact of a coupled reaction.

\subsection{Standard Electrode Potential $\left(\mathrm{E}^{\circ}\right)$ Analysis}

Results showed a little difference in the values of $\mathrm{E}^{\circ}$ for the forward and reverse scan as seen in Table 3 , which might be due to resistance of the solution as the concentration or metal ligand ratio was increased. Irreversibility in chemical reaction or heterogeneous electron transfer may be other causes. 
Table 2 Electrochemical parameters obtained from cyclic voltammograms of Co(II)-thymoquinone complex solutions with different metal-ligand ratios $(\mathrm{n}=3)$.

\begin{tabular}{|c|c|c|c|c|}
\hline Ratio L/M & $\frac{\mathrm{E}_{\mathrm{pa}}( \pm \mathrm{SD})^{*}}{/ \mathrm{V}}$ & $\underset{\mathrm{pa}}{\mathrm{I}_{\mathrm{A}}( \pm \mathrm{SD})} \times 10^{-5}$ & $\mathrm{I}_{\mathrm{pa}} / \mathrm{I}_{\mathrm{pc}}( \pm \mathrm{SD})$ & $\begin{array}{c}\beta \mathrm{n}_{\mathrm{b}}= \\
0.048 / \mathrm{E}_{\mathrm{pa}}-\mathrm{E}_{\mathrm{pa} / 2}( \pm \mathrm{SD})\end{array}$ \\
\hline 1 & - & - & - & - \\
\hline 2 & $-0.238 \pm 0.01$ & $1.917 \pm 0.01$ & $0.504 \pm 0.01$ & $0.758 \pm 0.01$ \\
\hline 3 & $-0.245 \pm 0.01$ & $2.188 \pm 0.01$ & $0.430 \pm 0.01$ & $0.857 \pm 0.02$ \\
\hline 4 & $-0.248 \pm 0.01$ & $3.550 \pm 0.01$ & $0.515 \pm 0.01$ & $0.889 \pm 0.01$ \\
\hline 5 & $-0.255 \pm 0.02$ & $3.778 \pm 0.02$ & $0.418 \pm 0.02$ & $0.887 \pm 0.02$ \\
\hline Ratio L/M & $\begin{array}{c}\mathrm{E}_{\mathrm{pc}}( \pm \mathrm{SD}) \\
/ \mathrm{V}\end{array}$ & $\mathrm{I}_{\mathrm{pc}}( \pm \mathrm{SD}) \times 10^{-5}$ & $\Delta \mathrm{E}=\underset{\mathrm{pa}}{\mathrm{E}_{\mathrm{p}}-\mathrm{E}_{\mathrm{pc}}( \pm \mathrm{SD})}$ & $\begin{array}{c}\alpha \mathrm{n}_{\mathrm{a}}= \\
0.048 / \mathrm{E}_{\mathrm{pc}}-\mathrm{E}_{\mathrm{p} c / 2}( \pm \mathrm{SD})\end{array}$ \\
\hline 1 & $-0.302 \pm 0.01$ & $1.743 \pm 0.01$ & - & $0.797 \pm 0.01$ \\
\hline 2 & $-0.324 \pm 0.01$ & $3.804 \pm 0.01$ & $0.086 \pm 0.01$ & $0.774 \pm 0.01$ \\
\hline 3 & $-0.326 \pm 0.02$ & $5.090 \pm 0.01$ & $0.081 \pm 0.01$ & $0.855 \pm 0.01$ \\
\hline 4 & $-0.338 \pm 0.01$ & $6.896 \pm 0.01$ & $0.090 \pm 0.01$ & $0.797 \pm 0.01$ \\
\hline 5 & $-0.349 \pm 0.02$ & $9.029 \pm 0.02$ & $0.094 \pm 0.02$ & $0.787 \pm 0.02$ \\
\hline
\end{tabular}

${ }^{*} \mathrm{SD}=$ standard deviation.

Table 3 Standard electrode potential $\left(\mathrm{E}^{\circ}\right)$ and diffusion coefficient (D) for $\mathrm{Co}(\mathrm{II})$-thymoquinone complex at different concentrations and metal-ligand ratios.

\begin{tabular}{|c|c|c|c|c|c|}
\hline Conc. $\left(\times 10^{-3} \mathrm{M}\right)$ & $\begin{array}{c}\left(E^{\circ}\right)_{a} \\
/ V\end{array}$ & $\begin{array}{c}\mathrm{D} \\
/ \mathrm{cm}^{2} \mathrm{~s}^{-1}\end{array}$ & Ratio L/M & $\begin{array}{l}\left(\mathrm{E}^{\circ}\right)_{\mathrm{a}} \\
/ \mathrm{V}\end{array}$ & $\begin{array}{c}\mathrm{D} \\
/ \mathrm{cm}^{2} \mathrm{~s}^{-1}\end{array}$ \\
\hline 0.4 & $0.268 \pm 0.01$ & $3.12 \times 10^{-5}$ & 2 & $0.269 \pm 0.01$ & $4.08 \times 10^{-5}$ \\
\hline 0.6 & $0.270 \pm 0.01$ & $2.02 \times 10^{-5}$ & 3 & $0.273 \pm 0.01$ & $5.32 \times 10^{-5}$ \\
\hline 0.8 & $0.270 \pm 0.02$ & $2.63 \times 10^{-5}$ & 4 & $0.275 \pm 0.02$ & $1.40 \times 10^{-4}$ \\
\hline 1.0 & $0.274 \pm 0.01$ & $3.09 \times 10^{-5}$ & 5 & $0.279 \pm 0.02$ & $1.59 \times 10^{-4}$ \\
\hline 1.2 & $0.276 \pm 0.02$ & $3.23 \times 10^{-5}$ & - & - & - \\
\hline Conc. $\left(\times 10^{-3} \mathrm{M}\right)$ & $\begin{array}{l}\left(\mathrm{E}^{\circ}\right)_{\mathrm{c}} \\
/ \mathrm{V}\end{array}$ & $\begin{array}{c}\mathrm{D} \\
/ \mathrm{cm}^{2} \mathrm{~s}^{-1}\end{array}$ & Ratio L/M & $\begin{array}{l}\left(\mathrm{E}^{\circ}\right)_{\mathrm{c}} \\
/ \mathrm{V}\end{array}$ & $\begin{array}{c}\mathrm{D} \\
/ \mathrm{cm}^{2} \mathrm{~s}^{-1}\end{array}$ \\
\hline 0.4 & $0.302 \pm 0.01$ & $4.28 \times 10^{-4}$ & 2 & $0.293 \pm 0.01$ & $1.61 \times 10^{-4}$ \\
\hline 0.6 & $0.308 \pm 0.01$ & $3.40 \times 10^{-4}$ & 3 & $0.299 \pm 0.02$ & $2.88 \times 10^{-4}$ \\
\hline 0.8 & $0.317 \pm 0.01$ & $2.99 \times 10^{-4}$ & 4 & $0.309 \pm 0.01$ & $5.28 \times 10^{-4}$ \\
\hline 1.0 & $0.321 \pm 0.02$ & $2.68 \times 10^{-4}$ & 5 & $0.318 \pm 0.02$ & $9.06 \times 10^{-4}$ \\
\hline 1.2 & $0.327 \pm 0.01$ & $2.35 \times 10^{-4}$ & - & - & - \\
\hline
\end{tabular}

\section{Conclusion}

Quantitative studies of Co(II)-thymoquinone complex were carried out using cyclic voltammetry. Results suggested that the complex followed quasi-reversible mechanism. The study indicates that linear regression can be applied for quantification of the studied complex within a wide linear range i.e. $0.02 \times 10^{-3} \mathrm{M}$ to $1.2 \times 10^{-3} \mathrm{M}$ successfully. The complex seems to be stable at lower concentrations and a high concentration seems to destabilize the complex.In both cases, by increasing metal-ligand ratio and concentration of complex solutions an additional oxidative peak was observed, the reason for which may be any possible reaction between the oxidized species and the solvent but the absence of a reverse peak indicates instability of this additional complex. In addition, values of different electrochemical parameters including $\mathrm{E}^{\circ}, \mathrm{D}, \alpha$ and $\beta$ were also determined at different concentrations and metal-ligand ratios.

\section{References}

1 H.D. Riordan, N. Mikirova, P.R. Taylor, C.A. Feldkamp and J.J. Casciari, The effects of a primary nutritional deficiency (vitamin B study), Food Nutr. Sci., 2012, 3, 1238-1244.

2 E.N. Whitney and S.R.Rolfes, Understanding Nutrition, 9th edn., Wadsworth, Belmont, USA, 2002.
3 A. Imbard, J.F. Benoist and H.J.Blom, Neural tube defects, folic acid and methylation, Int. J. Environ. Res. Public Health, 2013, 10, 4352-4389.

4 R. Oh and D.L. Brown, Vitamin B-12 deficiency, Am. Fam. Physician, 2003, 67, 979-986.

5 R. Banerjee, Chemistry and Biochemistry of B12, John Wiley \& Sons, New York, 1999.

6 H.W. Baik and R.M. Russell, Vitamin $B_{12}$ deficiency in the elderly, Anпu. Rev. Nutr., 1999, 19, 357-377.

7 F. Nourhashemi, S. Gillette-guyonnet and S. Andrieu, Weight loss in Alzheimer disease, Am. J. Clin. Nutrit., 2000, 71, 643S-649S.

8 A.G. Sharpe, Inorganic Chemistry, 3rd edn., Longman Singapore Publishers, Singapore, 1996.

9 F.A. Cotton and G. Wilkinson, Advanced Inorganic Chemistry, 5th edn., John Wiley \& Sons, Canada, 1988.

10 G. Singh, P. Marimuthu, C.S. deHeluani and C. Catalan, Chemical constituents and antimicrobial and antioxidant potentials of essential oil and acetone extract of Nigella sativa seeds, J. Sci. Food Agr, 2005, 85, 2297-2306.

11 F. Benkaci-Ali, A. Baaliouamer, J.P. Wathelet and M. Marlier, Etude comparative de la composition chimique de la Nigella sativa de quelques régions du monde, extraite par micro-ondes, Riv. Ital., EPPOS, 2006, 41, 23-32.

12 H.Y. Aboul-Enein and L.I.Abou-Basha, Simple HPLC method for the determination of thymoquinone in black seed oil (Nigella sativa Linn), J. Liq. Chromatogr., 1995, 18, 895-902. 
13 O.A. Badary, M.F. Abd-Ellah, M.A. El-Mahdy, S.A. Salama and F.M. Hamada, Anticlastogenic activity of thymoquinone against benzo (a) pyrene in mice, Food Chem. Toxicol., 2007, 45, 88-92.

14 A.A. Syed, Thymoquinone protects renal tubular cells against tubular injury, Cell Biochem. Funct., 2008, 26, 374-380.

15 H. Gali-Muhtasib, M. Ocker, D. Kuester, S. Krueger, Z. El-Hajj, A. Diestel, M. Evert, N. El-Najjar, B. Peter, A. Jurjus, A. Roessner and R. Schneider-Stock, Thymoquinone reduces mouse colon tumor cell invasion and inhibits tumor growth in murine colon cancer models, J. Cell. Mol. Med., 2008, 12, 330-342.

16 M.A. El-Mahdy, Q. Zhu, Q.E. Wang, G. Wani and A.A. Wani, Thymoquinone induces apoptosis through activation of caspase-8 and mitochondrial events in p53-null myeloblastic leukemia HL-60 cells, Int. J. Cancer, 2005, 117, 409-417.

17 M.A. Mansour, M.N. Nagi, A.S. El-Khatib and A.M. Al-Bekairi, Effects of thymoquinones on antioxidant enzyme activities, lipid peroxidation and DT-diaphorase in different tissues of mice: a possible mechanism of action. Cell Biochem. Func., 2002, 20, 143-151.

18 O.A. Badary, R.A. Taha, A.M.Gamal el-Din and M.H. Abdel-Wahab, Thymoquinone is a potent superoxide anion scavenger, Drug Chem. Toxicol., 2003, 26, 87-98.

19 F. Kishwar, Q. Haq and H. Anwar, Use of active ingredient of Nigella sativa to reduce toxicity of some trace elements (Fe(III), $\mathrm{Cr}(\mathrm{VI}), \mathrm{Cu}(\mathrm{II})$ V(IV) and Co(II)), FUUAST J. Biol., 2012, 2, 95-101.

20 F. Kishwar and Q. Haq, Cyclic voltammetric studies of thymoquinone with iron (III), Pak. J. Sci. Ind. Res, 2013, 56, 59-69.

21 J. Wang, Analytical Electrochemistry, 2nd edn.,VCH Publishers, New York, 1994.

22 A.J. Bard and L.R. Faulkner, Electrochemical Methods: Fundamentals and Applications, John Wiley \& Sons, New York, 1980.
23 R.D. Braun, Introduction to Chemical Analysis, International Student Edition, McGraw-Hill Book Co., Singapore, 1983.

24 D.A. Skoog, FJ. Holler and T.A. Nieman, Principles of Instrumental Analysis, 5th edn., Saunders College Publishing, Harcourt Brace College Publishers, USA, 1998.

25 S.E. Baghbamidi, H. Beitollahi, H. Karimi Maleh, S.S. Nejad, V.S. Nejad and S. Roodsaz, Modified carbon nanotube paste electrode for voltammetric determination of carbidopa, folic acid, and tryptophan, J. Anal. Methods Chem., 2012, 2012, 8 pp.

26 H. Beitollahi, and M. Mostafavi, Nano structured base electrochemical sensor for simultaneous quantification and voltammetric studies of levodopa and carbidopa in pharmaceutical products and biological samples. Electroanal., 2014, 26, 1090-1098.

27 E. Molaakbari, A. Mostafavi, H. Beitollahi and R. Alizadeh, Synthesis of $\mathrm{ZnO}$ nano rods and their application in the construction of a nanostructure-based electrochemical sensor for determination of levodopa in the presence of carbidopa, Analyst, 2014, 139, 4356-4364.

$28 \mathrm{H}$. Beitollahi, I. Sheikhshoaie, Selective voltammetric determination of norepinephrine in the presence of acetaminophen and folic acid at a modified carbon nanotube paste electrode, J. Electroanal. Chem., 2011, 661, 336-342.

29 H. Beitollahi,A. Mohadesi,S. Mohammadi and A. Akbari, Electrochemical behavior of a carbon paste electrode modified with 5-amino-3', $4^{\prime}$-dimethyl-biphenyl-2-ol/carbon nanotube and its application for simultaneous determination of isoproterenol, acetaminophen and N-acetylcysteine. Electrochim. Acta, 2012, 68, 220-226.

30 R. Greef, R. Peat, L.M. Reter, D. Pletcher and J. Robinson, Instrumental Methods in Electrochemistry, 1st edn., John Wiley and Sons, New York, USA, 1985.

31 H. Anwer, Complexation of Vanadyl Compounds with Maltol, Ph.D. dissertation, University of Karachi, Karachi, Pakistan, 2006, 213. 